ISSN 1823-626X

Malaysian Journal of Fundamental and Applied Sciences

available online at http://mjfas.ibnusina.utm.my

\title{
A New Proof on Sequence of Fuzzy Topographic Topological Mapping
}

\author{
Azrul Azim Mohd Yunus ${ }^{1} \&$ Tahir Ahmad $^{2 *}$ \\ ${ }^{1}$ Department of Mathematical Sciences, Faculty of Science, UTM, 81310 UTM Skudai, Johor, Malaysia \\ ${ }^{2}$ Ibnu Sina Institute for Fundamental Science Studies, UTM, 81310 UTM Skudai, Johor, Malaysia \\ Received 8 January 2013, Revised 30 March 2013, Accepted 16 April 2013, Available online 20 May 2013
}

\begin{abstract}
Fuzzy Topological Topographic Mapping (FTTM) is a model for solving neuromagnetic inverse problem. FTTM consists of four components and connected by three algorithms. FTTM version 1 and FTTM version 2 were designed to present $3 D$ view of an unbounded single current and bounded multicurrent source, respectively. In 2008, Suhana proved the conjecture posed by Liau in 2005 such that, if there exists $n$ number of FTTM, then $n^{4}-n$ new elements of FTTM will be generated from it. Suhana also developed some new definitions on geometrical features of FTTM, and discovered some interesting algebraic properties. In this paper, new proof on sequence of FTTM will be presented. In the proof, the sequence of FTTM is transformed into a system of differential equation.
\end{abstract}

| Fuzzy topographic topological mapping | Number Theory | Sequence | Differential Equation |

® 2013 Ibnu Sina Institute. All rights reserved. http://dx.doi.org/10.11113/mjfas.v9n4.106

\section{INTRODUCTION}

FTTM is a novel method for solving neuromagnetic inverse problem to determine the current source, i.e. epileptic foci. FTTM Version 1 is developed to present a 3$\mathrm{D}$ view of an unbounded single current source $[1,2]$ in one angle observation (upper of a head model). It consists of three algorithms, which link between four components of the model as shown in Figure 1.

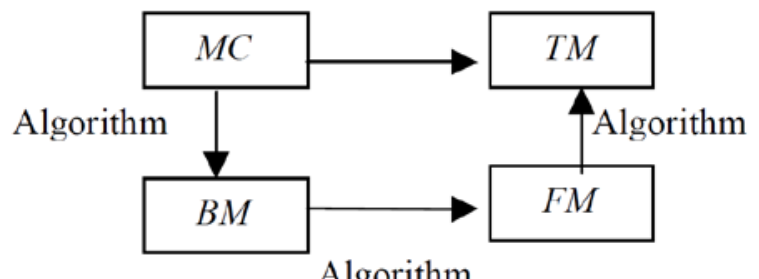

Fig. 1 FTTM version 1

The four components of FTTM are Magnetic Contour Plane $(M C)$, Base Magnetic Plane (BM), Fuzzy Magnetic Field $(F M)$ and Topographic Magnetic Field (TM) (Figure 1). $M C$ is a magnetic field on a plane above a current source with $z=0$. The plane is lowered down to $B M$, which is a plane of the current source with $z=-h$. Then the entire $B M$ is fuzzified into a fuzzy environment $(F M)$, where all the magnetic field readings are fuzzified. Finally, a three dimensional presentation of $F M$ is plotted on $B M$. The final process is defuzzification of the fuzzified data to obtain a 3-D view of the current source (TM).
FTTM Version 2 is developed to present 3-D view of a bounded multi current source [3] in 4 angles of observation (upper, left, right and back of a head model). It consists of three algorithms, which link between four components of the model. The four components are Magnetic Image Plane $(M I)$, Base Magnetic Image Plane $(B M I)$, Fuzzy Magnetic Image Field (FMI) and Topographic Magnetic Image Field (TMI) (Figure 2).

$M I$ is a plane above a current source with $z=0$ containing all grey scale readings (0DN-255DN) of magnetic field. The plane is lowered down to $B M I$, which is a plane of the current source with $z=-h$. Then the entire base $B M I$ is fuzzified into a fuzzy environment $(F M I)$, where all the gray scale readings are fuzzified. Finally, a three dimensional presentation of FMI is plotted on BMI. The final process is defuzzification of the fuzzified data to obtain a 3-D view of the current source (TMI).

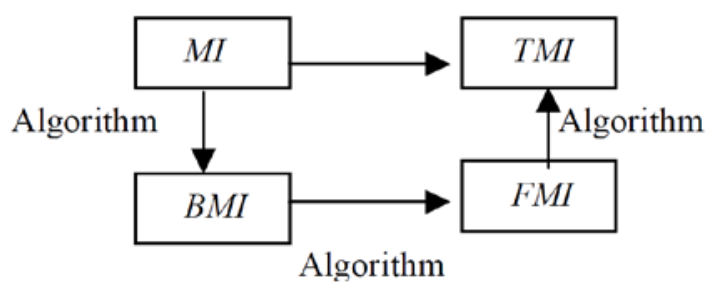

Fig. 2 FTTM version 2

FTTM Version 1 and FTTM Version 2 are specially designed to have equivalent topological structures between their components [4]. In other words, a homeomorphism 
between each component of FTTM Version 1 and FTTM Version 2 exists [5] as shown in Figure 3.

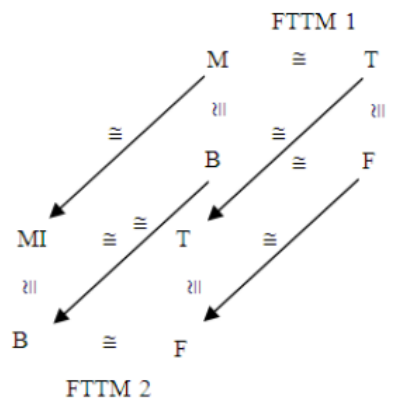

Fig. 3 Homemorphisms between FTTM 1 and FTTM 2

\section{MATERIALS AND METHODS}

Recall definitions on sequence, vertices, edges, vertices of FTTM [6].

\section{Definition 1 FTTM [6]}

Generally, FTTM can be represented as

$$
F T T M=\{(M, B, F, T): M \cong B \cong F \cong T\}
$$

In order to extract some geometrical features of FTTM, the exact arrangement of sequence of FTTM is presented in Figure 4 [7].

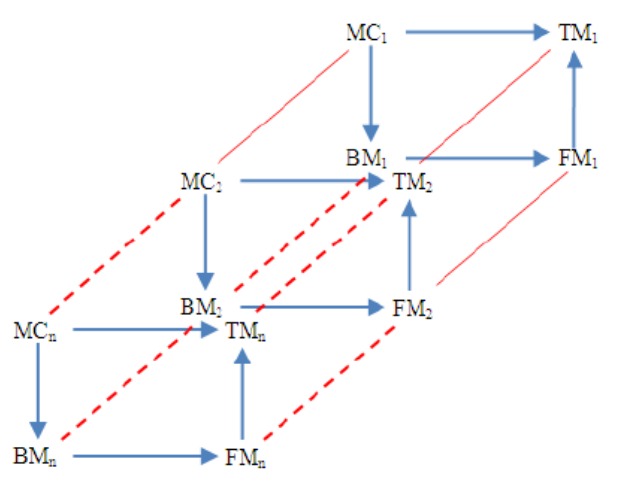

Fig. 4 Sequence of $F T T M_{n}$

\section{Definition 2 Sequence of FTTM [7]}

Let $F T T M_{i}=\left(M C_{i}, B M_{i}, F M_{i}, T M_{i}\right)$ such that $M C_{i}, B M_{i}, F M_{i}$, $T M_{i}$ are topological spaces with $M C_{i} \cong B M_{i} \cong F M_{i} \cong T M_{i}$. Sequence of $n F T T M_{i}$ of FTTM is FTTM 1, FTTM $_{2}$, $\mathrm{FTTM}_{3}, \ldots, \mathrm{FTTM}_{n}$ such that $M C_{i} \cong M C_{i+1}, B M_{i} \cong B M_{i+1}$, $F M_{i} \cong F M_{i+1}, T M_{i} \cong T M_{i+1}$.

FTTM $_{1}$, FTTM $_{2}$, FTTM $_{3}$, and FTTM $_{4}$ are illustrated in Figure 5 respectively. FTTM $_{1}$ can be viewed generally as a square and with $M C, B M, F M$ and $T M$ as vertices and the homeomorphism, namely $M C \cong B M, B M \cong F M, F M \cong T M$ and $M C \cong T M$, as edges. $F T T M_{1}$ has 4 vertices and 4 edges.
FTTM $_{2}$ consists of 8 vertices, 12 edges, 6 faces and 1 cube. Generally a cube is a combination of 2 FTTM. FTTM $_{3}$ consists of 12 vertices, 24 edges, 15 faces and 3 cubes. FTTM $_{4}$ has 16 vertices, 28 edges, 16 faces and 6 cubes. Consequently, some patterns of vertices, edges, faces and cubes emerge from sequences of FTTM as listed in the Table I.

Figure 5. a) $\mathrm{FTTM}_{1}$, b)FTTM 2 , c) $\mathrm{FTTM}_{3}$, d)FTTM

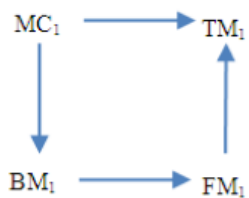

(a)

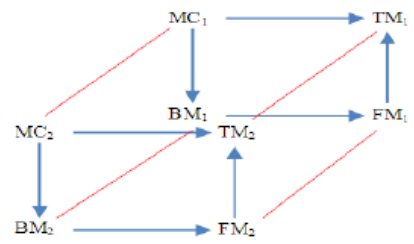

(b)

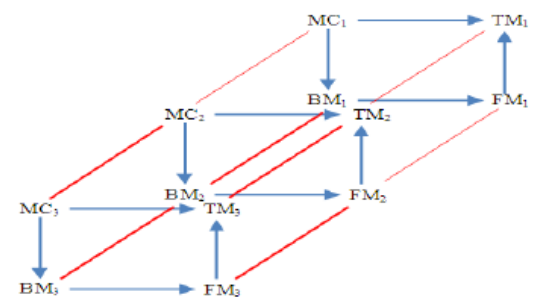

(c)

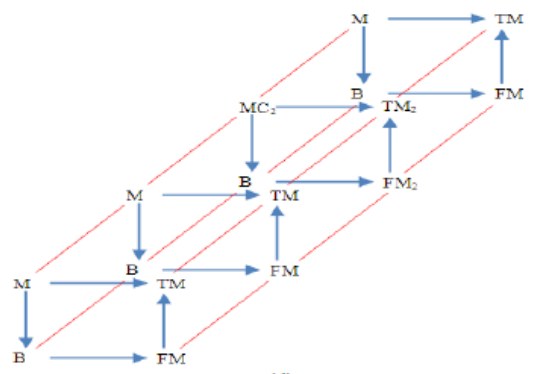

(d)

Definition 3 Sequence of Vertices of $\operatorname{FTTM}_{n}$ [6]

The sequence of vertices for $F_{T T M}$ which is $v F T T M_{n}$ are given recursively by equation

$v$ FTTM $_{n}=v$ FTTM $_{n-1}+4$ for $n \geq 1$ and $v \operatorname{FTTM}_{0}=0$.

Definition 4 Sequence of Edges of $\operatorname{FTTM}_{n}$ [6]

The sequence of edges for $\mathrm{FTTM}_{n}$ which is $e F T T M_{n}$ are given recursively by equation

$e \mathrm{FTTM}_{n}=e \mathrm{FTTM}_{n-1}+8$ for $n>1$ and $e \mathrm{FTTM}_{1}=4$.

Definition 5 Sequence of Faces of $F_{T T M}$ [6] 
The sequence of face for $\mathrm{FTTM}_{n}$ which is $\mathrm{FTTM}_{n}$ are given recursively by equation

$f$ FTTM $_{n}=f F T T M_{n-1}+5$ for $n>1$ and FFTTM $_{1}=1$.

Definition 6 Sequence of cubes of $F_{T T M}$ [6]

The sequence of cubes for $F T T M_{n}$ which is $F_{T T M} / 1$, $F_{T T M} / 2, F T T M_{2 / 3}, .$. , are given recursively by equation

FTTM $_{2 / n}=\operatorname{FTTM}_{2 / n-1}+(n-1)$ for $n \geq 1$ and

$\operatorname{FTTM}_{2 / 0}=0$.

Table 1 show the vertices, edges, faces and cubes for some sequences of FTTM [6].

Table 1 Vertices, Edges, Faces and Cubes for Sequence of FTTM

\begin{tabular}{lrrrr}
\hline FTTM $_{n}$ & Vertices & Edges & Faces & Cubes \\
\hline FTTM $_{1}$ & 4 & 4 & 1 & 0 \\
FTTM $_{2}$ & 8 & 12 & 6 & 1 \\
FTTM $_{3}$ & 12 & 20 & 11 & 3 \\
FTTM $_{4}$ & 16 & 28 & 16 & 6 \\
FTTM $_{5}$ & 20 & 36 & 21 & 10 \\
FTTM $_{6}$ & 24 & 44 & 26 & 15 \\
FTTM $_{7}$ & 28 & 52 & 31 & 21 \\
FTTM $_{8}$ & 32 & 60 & 36 & 28 \\
FTTM $_{9}$ & 36 & 68 & 41 & 36 \\
FTTM $_{10}$ & 40 & 76 & 46 & 45 \\
\hline
\end{tabular}

From the table and definitions above, several new theorems on sequence of FTTM can be deduced and presented in following section.

\section{A NEW PROOF ON SEQUENCE OF FTTM}

Proving the sequence of FTTM can be very tedious as it involves large sequence of numbers. The previous method [8] of proving sequence of FTTM was by proof by construction. However this method required one to develop geometrical features for all sequence of FTTM [9]. However, in this section an alternative method of proving sequence of FTTM is presented, namely by method of differential equations [10].

\subsection{Theorem 1}

The Sequence of edges of $F_{T T M} ;$ eFTTM $_{n}$ can be represented as

$$
e \operatorname{FTTM}_{n}=8 n-4
$$

Proof:

Recall Definition 4, sequence of edges can be defined as

$$
e \text { FTTM }_{n-1}=e \text { FTTM }_{n}+8
$$

Equivalently,

$$
e \operatorname{FTTM}_{n+1}-e \operatorname{FTTM}_{n}=8
$$

Equation (5) can be viewed as a non-homogenous ordinary differential equation as follows

$$
\operatorname{eFTTM}_{n}=S_{n}+T_{n}
$$

with $S_{n}$ is the general solutions

$$
S_{n+1}-S_{n}=0
$$

and $T_{n}$ is particular solutions such that

$$
T_{n+1}-T_{n}=8
$$

Equation (7) can be solved by finding the related polynomial for equation (5). In this case, the related polynomial for (5) is

$$
\begin{aligned}
P(r) & =r-1 \\
& =0
\end{aligned}
$$

which implies $r=1$. Solution for (7) is given by $S_{n}=A r$.

$$
\therefore S_{n}=A
$$

To get solution for (8), let

$$
T_{n}=B n
$$

Substituting $T_{n}$ into (8) will gives

$$
\begin{aligned}
T_{n+1}-T_{n} & =8 \\
B(n+1)-B n & =8 \\
B & =8 \\
\therefore T_{n} & =8 n
\end{aligned}
$$

From (9) and (11), solution for (6) can be written as

$$
\text { eFTTM }_{n}=8 n+A
$$

From Table I, initial values for $e F T T M_{1}=4$ which implies $A=-4$.

$$
\therefore e \text { FTTM }_{n}=8 n-4
$$

\subsection{Theorem 2}

The Sequence of faces of $F T T M_{n} ;$ fFTTM $_{n}$ can be represented as

$$
\operatorname{fFTTM}_{n}=5 n-4
$$

Proof:

Recall Definition 5, sequence of edges can be defined as

Equivalently,

$$
\text { fFTTM }_{n}=\text { fFTTM }_{n-1}+5
$$

$$
\text { fFTTM }_{n+1}-\text { fFTTM }_{n}=5
$$

Similarly, equation (12) can be viewed as a nonhomogenous ordinary differential equation as follows

$$
\operatorname{fFTTM}_{n}=U_{n}+V_{n}
$$

with $S_{n}$ is the general solutions

$$
U_{n+1}-U_{n}=0
$$

and $T_{n}$ is particular solutions such that

$$
V_{n+1}-V_{n}=5
$$

Equation (14) can be solved by finding the related polynomial for equation (12). In this case, the related polynomial for (12) is 


$$
\begin{aligned}
P(r) & =r-1 \\
& =0
\end{aligned}
$$

which implies $r=1$. Solution for (14) is given by $U_{n}=A r$.

$$
\therefore U_{n}=A
$$

To get solution for (8), let

$$
V_{n}=B n
$$

Substituting $T_{n}$ into (8) will gives

$$
\begin{aligned}
V_{n+1}-V_{n} & =5 \\
B(n+1)-B n & =5 \\
B & =5 \\
\therefore V_{n} & =5 n
\end{aligned}
$$

From (9) and (11), solution for (6) can be written as

$$
\text { fFTTM }_{n}=5 n+A
$$

From Table I, initial value for $\mathrm{fFTTM}_{1}=1$ which implies $A=-4$.

$$
\therefore \operatorname{fFTTM}_{n}=5 n-4
$$

\subsection{Theorem 3}

The Sequence of cubes of FTTM $_{n} ; c$ FTTM $_{n}$ can be represented as

$$
\operatorname{cFTTM}_{n}=\frac{n(n-1)}{2}
$$

Proof:

Recall definition 6, sequence of edges can be defined as

$$
\operatorname{cFTTM}_{n}=\operatorname{cFTTM}_{n-1}+n
$$

Equivalently,

$$
c \text { FTTM }_{n+1}-\text { cFTTM }_{n}=n
$$

Equation (19) can be viewed as a non-homogenous ordinary differential equation as follows

$$
c \text { FTTM }_{n}=W_{n}+Z_{n}
$$

with $W_{n}$ is the general solutions

$$
W_{n+1}-W_{n}=0
$$

and $Z_{n}$ is particular solutions such that

$$
Z_{n+1}-Z_{n}=n
$$

Equation (21) can be solved by finding the related polynomial for equation (19). In this case, the related polynomial for (19) is

$$
\begin{aligned}
P(r) & =r-1 \\
& =0
\end{aligned}
$$

which implies $r=1$. Solution for (21) is given by $W_{n}=A r$.

$$
\therefore W_{n}=A
$$

To get solution for (22), let

$$
Z_{n}=B n^{2}
$$

Substituting $T_{n}$ into (22) will gives

$$
\begin{array}{r}
B=\frac{1}{2} \\
\therefore V_{n}=\frac{1}{2} n^{2}
\end{array}
$$

Using (23) and (25), solution for (20) is follows

$$
\text { cFTTM }_{n}=A+\frac{1}{2} n^{2}
$$

From the Table I, initial value for $c F T T M_{1}=0$ which implies $A=-\frac{1}{2}$.

$$
\therefore \operatorname{cFTTM}_{n}=\frac{n(n-1)}{2}
$$

\subsection{CONCLUSION}

The aim of this paper is to produce new proof on sequence of edges, faces and cubes of FTTM.

Table II, III, IV show sequences of edges, faces, and cubes of $F T T M_{n}$, respectively. As a result, the number of sequence of edges, faces, and cubes are exactly the same as defined in [6].

Table II Comparison between sequences of Edges to Definition 4

\begin{tabular}{ccc}
\hline$e \mathrm{FTTM}_{n}$ & $e F T T M_{n-1}+8$ & $-4+8 n$ \\
\hline $\mathrm{n}=1$ & 4 & 4 \\
$\mathrm{n}=2$ & 12 & 12 \\
$\mathrm{n}=3$ & 20 & 20 \\
$\mathrm{n}=4$ & 28 & 28 \\
$\mathrm{n}=5$ & 36 & 36 \\
$\mathrm{n}=6$ & 44 & 44 \\
$\mathrm{n}=7$ & 52 & 52 \\
$\mathrm{n}=8$ & 60 & 60 \\
$\mathrm{n}=9$ & 68 & 68 \\
$\mathrm{n}=10$ & 76 & 76 \\
\hline
\end{tabular}

Table III Comparison between sequences of Faces to Definition 5

\begin{tabular}{ccc}
\hline$f \mathrm{FTTM}_{n}$ & $f F T T M_{n-1}+5$ & $-4+5 n$ \\
\hline $\mathrm{n}=1$ & 1 & 1 \\
$\mathrm{n}=2$ & 6 & 6 \\
$\mathrm{n}=3$ & 11 & 11 \\
$\mathrm{n}=4$ & 16 & 16 \\
$\mathrm{n}=5$ & 21 & 21 \\
$\mathrm{n}=6$ & 26 & 26 \\
$\mathrm{n}=7$ & 31 & 31 \\
$\mathrm{n}=8$ & 36 & 36 \\
$\mathrm{n}=9$ & 41 & 41 \\
$\mathrm{n}=10$ & 46 & 46 \\
\hline
\end{tabular}


Table IV Comparison between sequences of Cubes to Definition 6

\begin{tabular}{ccc}
\hline$c$ FTTM $_{n}$ & $F T T M_{2 / n-1}+(n-1)$ & $\frac{n(n-1)}{2}$ \\
\hline $\mathrm{n}=1$ & 0 & 0 \\
$\mathrm{n}=2$ & 1 & 1 \\
$\mathrm{n}=3$ & 3 & 3 \\
$\mathrm{n}=4$ & 6 & 6 \\
$\mathrm{n}=5$ & 10 & 10 \\
$\mathrm{n}=6$ & 15 & 15 \\
$\mathrm{n}=7$ & 21 & 21 \\
$\mathrm{n}=8$ & 28 & 28 \\
$\mathrm{n}=9$ & 36 & 36 \\
$\mathrm{n}=10$ & 45 & 45 \\
\hline
\end{tabular}

\section{ACKNOWLEDGEMENT}

Author wants to thanks the members of Theoretical \& Computational Modeling for Complex Systems (TCM), Department of Mathematical Sciences \& Ibnu Sina Institute for Fundamental Science Studies, UTM, for their cooperation.

\section{REFERENCES}

[1] Ahmad, T., Ahmad, R. S., Zakaria, F., and Yun., L. L. Development of detection model for neuromagnetic fields. Proceeding of Biomed September 27-28, 2000, Kuala Lumpur, Universiti Malaya, 2000.

[2] Zakaria, F., Algoritma Penyelesaian Masalah Songsang Arus Tunggal Tak Terbatas MEG, M.S.thesis, Universiti Teknologi Malaysia, 2002.

[3] Rahman, W. E. Z. W. A., Ahmad, T., and Ahmad, R. S., Simulating the Neuronal Current Sources in the Brain. Proceeding BIOMED. September 27-28, 2002, Kuala Lumpur Universiti Malaysia, 2002.

[4] Yun, L. L., Homeomorfisma $s^{2}$ antara $e^{2}$ Melalui Struktur Permukaan Riemann Serta Deduksi Teknik Pembuktiannya Bagi Homeomorfisma Pemetaan Topologi Topografi Kabur, M.S. thesis, Universiti Teknologi Malaysia, 2001.

[5] Ahmad, T., Ahmad, R. S., Yun, L.L., Zakaria, F., and Rahman, W. E. Z. W. A., Matematika, 21(1) (2005) 35-42.

[6] Jamaian, S. S. 2008. Generalized fuzzy topographic topological mapping. M.S. thesis, Universiti Teknologi Malaysia, 2008.

[7] Jamaian, S. S., Ahmad, T., and Talib, J., Journal of Mathematics and Statistics, 6(2) (2010) 151-156.

[8] Hein, J.L., Discreate Mathematics (2nd Edition), Jones and Bartlett Publishers, 2003.

[9] Sanugi, B., Matematika, 9(1) (1993) 23-27.

[10] Lambert, J., Kaedah Pengiraan Dalam Persamaan Pembeza Biasa (Terjemahan), Dewan Bahasa dan Pustaka, Malaysia, 1990. 